\title{
38 Fat distribution patterns, their measurands and the risk of dementia
}

The standard measure of body fat is the body mass index (BMI). It is calculated from the body mass (weight in $\mathrm{kg}$ ) divided by height in meters squared $\left(\mathrm{m}^{2}\right)$. A normal BMI is found in $65 \%$ of 25 - to 34 -year-old women and in $50 \%$ of the same-aged men. Thirty years later, only approximately one in every three women or men will have a normal weight (•Tab. 38.1).

$\mathrm{BMI}$ is not the only measurand used to characterize the multiplying number of fat pads in the body. The distribution of the excess adipose tissue is also of great importance. A simple measure of fat distribution patterns is the ratio of waist to hip size. Accordingly, it is harmful to health when this ratio is greater than 0.85 in women and 1.00 in men. An even faster way to determine abdominal obesity is by just measuring the waist circumference alone. The risk of disease increases with a girth of more than $80 \mathrm{~cm}$ in women and $94 \mathrm{~cm}$ in men and is significantly elevated in circumferences of exceeding 88 and $102 \mathrm{~cm}$, respectively.

An accumulation of fat pads in the abdominal organs, especially in the liver, can also lead to increased mortality rates ( $\downarrow$ Chapter 43 ). A special measure for estimating the obesity-related mortality hazard is called the ABSI ("a body shape index"). It is calculated from weight, body height and waist circumference (Krakauer et Krakauer 2014).

According to the results of studies conducted in the United States with observation periods spanning several decades, one of the many hazard

\begin{tabular}{|c|c|c|}
\hline \multicolumn{3}{|c|}{$\begin{array}{l}- \text { Tab. 38.1 Body weight classification in stages } \\
\text { according to WHO guidelines }\end{array}$} \\
\hline \multicolumn{2}{|c|}{ Classification } & $\begin{array}{l}\text { Body Mass Index } \\
\text { (BMI) }\end{array}$ \\
\hline \multicolumn{2}{|c|}{ Underweight } & $<18$ \\
\hline \multicolumn{2}{|c|}{ Normal weight } & $18.5-24.9$ \\
\hline \multicolumn{2}{|c|}{ Overweight } & $25-29.9$ \\
\hline \multirow[t]{3}{*}{ Obese } & - Class I & $30-34.9$ \\
\hline & - Class II & $35-40.0$ \\
\hline & - Class III & $>40$ \\
\hline
\end{tabular}

potentials linked to central obesity ( $\downarrow$ Chapter 39) is the increased risk of dementia (Whitmer et al. 2008, Gelber et al. 2012). Especially obesity in midlife increases this risk (Xu et al. 2011). According to secondary analyses of the Framingham Heart Study, the brain volume of selected patients was lower the higher their BMI (Debette et al. 2010).

In approximately one fifth of overweight and obese persons, the genetically based growth in the number and size of fat cells is evenly distributed and the cells are distributed broadly throughout the subcutaneous compartment (Heid et al. 2010). Because fewer of the visceral biomarkers are released, weight-related health impairments become less manifest in this group of persons. 